\title{
Prevalence of asthma among Chinese adolescents living in Canada and in China
}

\author{
Hong-Yu Wang MD PhD, Gary W.K. Wong MD, Yu-Zhi Chen MD, Alexander C. Ferguson MB ChB, \\ Justina M. Greene, Yu Ma MD, Nan-Shan Zhong MD, Christopher K.W. Lai DM, \\ Malcolm R. Sears MB ChB
}

\section{ABSTRACT}

Background: Studies of the prevalence of asthma among migrating populations may help in identifying environmental risk factors.

Methods: We analyzed data from Vancouver, Canada, and from Guangzhou, Beijing and Hong Kong, China, collected during phase 3 of the International Study of Asthma and Allergies in Childhood. We subdivided the Vancouver adolescents according to whether they were Chinese immigrants to Canada, Canadian-born Chinese or Canadianborn non-Chinese. We compared the prevalence of asthma and wheezing among Chinese adolescents born in Canada, Chinese adolescents who had immigrated to Canada and Chinese adolescents living in China.

Results: Of 7794 Chinese adolescents who met the inclusion criteria, 3058 were from Guangzhou, 2824 were from Beijing, and 1912 were from Hong Kong. Of 2235 adolescents in Vancouver, Canada, 475 were Chinese immigrants, 617 were Canadian-born Chinese, and 1143 were Canadianborn non-Chinese. The prevalence of current wheezing among boys ranged from $5.9 \%$ in Guangzhou to $11.2 \%$ in Canadian-born Chinese adolescents. For girls, the range was $4.3 \%$ in Guangzhou to $9.8 \%$ in Canadian-born Chinese adolescents. The prevalence of ever having had asthma ranged from $6.6 \%$ to $16.6 \%$ for boys and from $2.9 \%$ to $15.0 \%$ for girls. Prevalence gradients persisted after adjustment for other environmental variables (odds ratios for ever having had asthma among Canadian-born Chinese compared with native Chinese in Guangzhou: 2.72 [95\% confidence interval 1.75-4.23] for boys and 5.50 [95\% confidence interval 3.21-9.44] for girls; $p<0.001$ for both). Among Chinese adolescents living in Vancouver, the prevalence of ever wheezing increased with duration of residence, from $14.5 \%$ among those living in Canada for less than 7 years to $20.9 \%$ among those living their entire life in Canada. The same pattern was observed for the prevalence of ever having had asthma, from $7.7 \%$ to $15.9 \%$.

Interpretation: Asthma symptoms in Chinese adolescents were lowest among residents of mainland China, were greater for those in Hong Kong and those who had immigrated to Canada, and were highest among those born in Canada. These findings suggest that environmental factors and duration of exposure influence asthma prevalence.

Une version française de ce résumé est disponible à l'adresse www.cmaj.ca/cgi/content/full/179/11/1133/DC1

CMAJ 2008;179(11):1133-42
$\mathrm{T}$ he prevalence of asthma symptoms exhibits large geographic variations, even among genetically similar groups,,${ }^{1,2}$ which suggests that differences may reflect variation in environmental factors. Epidemiologic studies have demonstrated associations between asthma and exposure to household allergens, ${ }^{3}$ pets,${ }^{4}$ environmental tobacco smoke ${ }^{5}$ and environmental pollution, ${ }^{6}$ as well as sex, ${ }^{7}$ obesity, ${ }^{8}$ number of siblings and birth order, ${ }^{9}$ and maternal education. ${ }^{10}$ Increasing "westernization" of environmental factors (such as changes in maternal diet, smaller family size, fewer infections during infancy, increased use of antibiotics and vaccination, less exposure to rural environments and improved sanitation) has been associated with an increased risk of childhood asthma. ${ }^{11}$ Conversely, the hygiene hypothesis proposed by Strachan in 1989 suggested that infections and contact with older siblings may reduce the risk of allergic diseases. ${ }^{12}$

Migration studies examining children of the same ethnic background living in different environments for part or all of their lives may help to identify factors relevant to the development of diseases and may explain some of the observed geographic variations in prevalence. In the International Study of Asthma and Allergies in Childhood, prevalence rates for asthma in Canada were among the highest in the world, whereas those in China were among the lowest. ${ }^{2}$ This difference could reflect genetic or environmental factors. China has been and continues to be a major source of international migration. ${ }^{13,14}$ Of immigrants in Vancouver, Canada, who landed between 1985 and 2001, half were born in East Asia, mainly Hong Kong and mainland China. ${ }^{15}$ Few studies on the prevalence of asthma among immigrants have been undertaken in Canada, ${ }^{16}$ and data for Chinese people living in Canada are not available.

We hypothesized that the prevalence of asthma would be highest among Canadian-born Chinese adolescents, lower

From the Guangzhou Institute of Respiratory Diseases (Wang, Zhong), First Affiliated Hospital of Guangzhou Medical College, Guangzhou, China; the Firestone Institute for Respiratory Health (Wang, Greene, Sears), St. Joseph's Healthcare, Hamilton, Ont.; the Department of Medicine (Wang, Greene, Sears), McMaster University, Hamilton, Ont.; the Department of Paediatrics (Wong), The Chinese University of Hong Kong, Shatin, Hong Kong, China; the Clinical and Education Centre for Asthma (Chen, Ma), Capital Institute of Paediatrics, Beijing, China; the Department of Pediatrics (Ferguson), University of British Columbia, Vancouver, BC; and the Department of Medicine and Therapeutics (Lai), The Chinese University of Hong Kong, Shatin, Hong Kong, China 
among Chinese adolescents who had immigrated to Canada and lowest among Chinese adolescents living in China. We further hypothesized that, among Chinese immigrants to Canada, prevalence rates of asthma would relate to duration of residence in Canada.

\section{Methods}

\section{Study design}

The study reported here was an analysis of data from phase 3 of the International Study of Asthma and Allergies in Childhood. This international study was a multiphase crosssectional study that began in 1991 to facilitate research into asthma, allergic rhinitis and eczema and to allow comparisons of the prevalence of these disorders between populations in different countries. In phase 1 , the researchers used simple core written questionnaires for 2 age groups (6-7 years and 13-14 years) to measure the prevalence of these conditions; a total of 721601 children (or their parents or guardians) in 156 centres in 56 countries completed the questionnaires. In phase 2, which involved more intensive studies in 30 centres in 22 countries, researchers investigated the variations in prevalence using objective measures such as skin examination, bronchial hyperresponsiveness, skin prick tests, measurement of serum immunoglobulin $\mathrm{E}$ and genetic studies and assessment of environment, lifestyle and clinical management. Phase 3, which commenced in 2001, was designed to examine variations in time trends of asthma, allergic rhinoconjunctivitis and atopic eczema using the same research design as phase 1, with a brief additional questionnaire to assess environmental factors. This phase involved a total of 498083 children in 110 centres in 58 countries, including 5 centres in Canada (Vancouver, Hamilton, Winnipeg, Saskatoon and Halifax) and 3 centres in China (Guangzhou, Beijing and Hong Kong).

\section{Study areas and populations}

For the current study, we analyzed data from the crosssectional phase 3 studies within the International Study of
Asthma and Allergies in Childhood, conducted in 1 centre in Canada with a large Chinese population (Vancouver, with 1.9 million inhabitants) and the 3 centres in China (Guangzhou, population 10 million; Beijing, population 12.8 million; and Hong Kong, population 6.7 million). The geographic, climatic and air pollution characteristics of these cities are detailed in Appendix 1 (available online at www.cmaj .ca/cgi/content/full/179/11/1133/DC2).

In each centre, the investigators recruited participants using schools as sampling units. The investigators assigned a number to each school from a defined geographic area in each city, and then randomized the schools in each area by computer. They selected a minimum of 10 schools to obtain a representative sample in each centre. The selected schools were situated within a relatively small area, with little variation in the urban environment; no schools were adjacent to major industrial pollution. Investigators identified the 2 school years with the highest proportion of children aged 13-14 years, and the children in these school years completed the phase 3 protocol. ${ }^{17}$

We retrospectively classified children in Vancouver as being of Chinese or non-Chinese ethnicity, on the basis of a published list of the 100 most common Chinese surnames. ${ }^{18}$ We defined Canadian-born status as having been born in Canada, with the years of residence in Canada being the same as the child's age. We defined an immigrant as having been born outside of Canada, with the years of residence in Canada being less than the child's age. We defined native Chinese as having been born in China (including Hong Kong), with the years of residence in China being the same as the child's age. For consistency among centres, we excluded children older than 14 years and those younger than 13 years from the analyses presented here.

\section{Questionnaires}

Each child recruited for the study completed the written questionnaire for phase 3 of the International Study of Asthma and Allergies in Childhood. Children in Vancouver completed the English questionnaire, and those in China completed a ver-

Table 1: Data from the process of identifying children for the International Study of Asthma and Allergies in Children from study centres in China and Vancouver

\begin{tabular}{|c|c|c|c|c|}
\hline Study feature & Guangzhou, China & Beijing, China & Hong Kong, China & Vancouver, Canada \\
\hline Study period & Nov-Dec 2001 & Oct-Nov 2001 & Apr-Jun 2002 & May 2003 \\
\hline No. of schools & 10 & 11 & 10 & 20 \\
\hline Response rate, \% & 96.0 & 99.0 & 99.0 & 79.6 \\
\hline No. of participants & 3516 & 3531 & 3321 & 2855 \\
\hline Age, yr, mean (SD) & $13.3(0.7)$ & $13.4(0.8)$ & $14.1 \quad(1.2)$ & $13.4(0.5)$ \\
\hline \multicolumn{5}{|c|}{$\begin{array}{l}\text { Age group, yr, no. (\%) of } \\
\text { participants }\end{array}$} \\
\hline 12 & $411(11.7)$ & $363(10.3)$ & $185 \quad(5.6)$ & $8(0.3)$ \\
\hline $13-14^{*}$ & 3067 (87.2) & $2857(80.9)$ & $2177(65.6)$ & $2823(98.9)$ \\
\hline 15 & 38 (1.1) & $311 \quad(8.8)$ & $959(28.9)$ & $24(0.8)$ \\
\hline
\end{tabular}

Note: SD = standard deviation.

*Included in the analysis presented here. 
sion of the questionnaire that had been translated into Chinese as described previously. ${ }^{19}$ The questionnaire had 8 questions about asthma-related symptoms in the past 12 months ("current" symptoms) or at any time in the child's lifetime ("ever" symptoms) and self-reported asthma ever. Other data collected consisted of the child's name, age, sex, self-reported anthropometric data (weight and height), birthplace and years of residence in the study country (or city), the number of siblings (younger or older), maternal education (primary school, secondary school or college), exposure to tobacco smoke (maternal or paternal), exposure to trucks (trucks passing the residential street frequently or almost all day) and having a pet at home (cat or dog).

The study protocol for phase 3 of the International Study of Asthma and Allergies in Childhood was approved by the Behavioural Sciences Research Review Committee, University of British Columbia in Vancouver, and the Ethics Committee of the Chinese University of Hong Kong for all 3 centres in China. The children's parents or guardians provided informed consent. In Vancouver, each child completed the questionnaire unless the parent declined the child's participation (passive consent).

\section{Statistical analysis}

The original researchers at each centre asked data entry personnel to double-enter all data from each centre into the database to ensure accuracy. In this report, we present numeric variables with non-normal distribution as medians and interquartile ranges and categorical variables as percentages. We calculated body mass index (BMI) from the self-reported anthropometric data, defining overweight and obesity according to the cut-points of BMI reported by Cole and colleagues. ${ }^{20}$

We used the Kruskal-Wallis nonparametric test to analyze differences among groups. We used univariable logistic regression analysis and multivariable logistic regression analysis to compare the prevalence rates of symptoms among different population groups and to evaluate the relation between symptoms of asthma and duration of residence in Canada. We adjusted the multivariable logistic regression analysis for confounding factors (sex, BMI, maternal education, number of siblings, order of siblings, parental smoking, truck exposure and having a pet at home, as described above). For Chinese adolescents living in Vancouver, we determined the median duration of residence in Canada and subdivided the participants on the basis of this cut-point: those residing in Canada for less than the median residence period, those residing in Canada for at least the median residence period but not for their entire life and those who had lived their entire lives in Canada. Results are presented as odds ratios (ORs) and 95\% confidence intervals (CIs), where odds ratios greater than 1 signify greater odds of having asthma-related symptoms (relative to the reference group). Differences were considered significant at $p<0.05$.

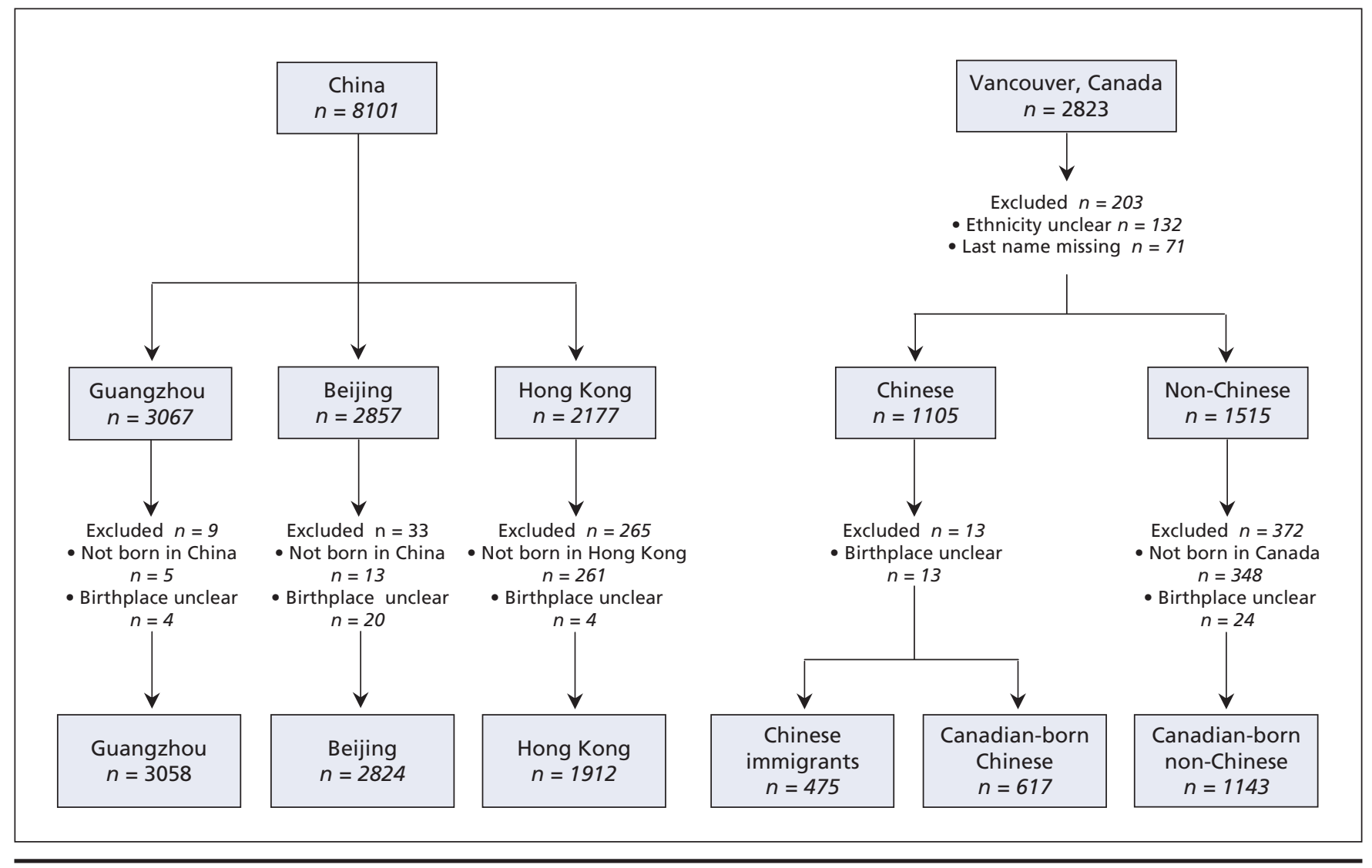

Figure 1: Flow diagram of study participants from among all 13- and 14-year-old children participating in phase 3 of the International Study of Asthma and Allergies in Childhood at study centres in China and Vancouver, Canada. 


\section{Results}

\section{Populations and demographic characteristics}

A total of 13223 schoolchildren from Vancouver and the 3 Chinese centres participated in phase 3 of the International Study of Asthma and Allergies in Childhood (Table 1). Of these, 10924 adolescents aged 13 or 14 years were included in this analysis: 8101 from China and 2823 from Vancouver. Using city and country of residence, ethnicity, birthplace and years of residence, we classified 10029 of these adolescents in 6 population subgroups (Figure 1). We excluded the re- maining 895 participants; 348 because they were non-Chinese adolescents who had not been born in Canada and 547 because their ethnicity or birthplace was uncertain.

There was a slightly greater proportion of boys in the Vancouver groups than in each group from China $(p<0.01)$ (Table 2). Median BMI and rates of overweight and obesity were lowest among native Chinese adolescents living in Guangzhou, whereas the prevalences of overweight and obesity were highest among Chinese adolescents living in Beijing and nonChinese adolescents in Vancouver. Maternal college education was more common among adolescents living in Vancouver

Table 2: Demographic, socioeconomic and environmental characteristics for the 6 selected groups of 13-to 14-year-old adolescents in China and Vancouver, from the International Study of Asthma and Allergies in Children

\begin{tabular}{|c|c|c|c|c|c|c|c|}
\hline \multirow[b]{2}{*}{ Characteristic } & \multicolumn{6}{|c|}{ Study group; no. (\%) of adolescents* } & \multirow[b]{2}{*}{$\begin{array}{c}p \\
\text { value }\end{array}$} \\
\hline & $\begin{array}{c}\text { Native } \\
\text { Chinese, } \\
\text { Guangzhou } \\
n=3058\end{array}$ & $\begin{array}{c}\text { Native } \\
\text { Chinese, } \\
\text { Beijing } \\
n=2824\end{array}$ & $\begin{array}{c}\text { Native } \\
\text { Chinese, } \\
\text { Hong Kong } \\
n=1912\end{array}$ & $\begin{array}{c}\text { Chinese } \\
\text { immigrants, } \\
\text { Vancouver } \\
n=475\end{array}$ & $\begin{array}{c}\text { Canadian- } \\
\text { born Chinese, } \\
\text { Vancouver } \\
n=617\end{array}$ & $\begin{array}{c}\text { Non-Chinese, } \\
\text { Vancouver } \\
n=1143\end{array}$ & \\
\hline Male & $1483(48.5)$ & $1437+(50.9)$ & $943(49.3)$ & $250(52.6)$ & $331(53.6)$ & $618(54.1)$ & 0.009 \\
\hline $\begin{array}{l}\mathrm{BMI}, \mathrm{kg} / \mathrm{m}^{2} \\
\text { median (IQR) }\end{array}$ & $17.97 \quad(3.08)$ & $19.14 \quad(4.84)$ & $18.74 \quad(3.51)$ & $18.93 \quad(3.38)$ & $19.18 \quad(3.72)$ & $19.78 \quad(3.91)$ & $<0.001$ \\
\hline BMI‡ & & & & & & & $<0.001$ \\
\hline Normal weight & $2648(86.6)$ & $2124(75.2)$ & $1653(86.5)$ & $348(73.3)$ & $455(73.7)$ & $824(72.1)$ & \\
\hline Overweight & $209(6.8)$ & $417(14.8)$ & $202(10.6)$ & $48(10.1)$ & $77(12.5)$ & $167(14.6)$ & \\
\hline Obesity & $55(1.8)$ & $199(7.0)$ & $44(2.3)$ & $15(3.2)$ & $22(3.6)$ & $56 \quad(4.9)$ & \\
\hline Missing data & $146(4.8)$ & $84 \quad(3.0)$ & $13(0.7)$ & $64(13.5)$ & $63(10.2)$ & $96 \quad(8.4)$ & \\
\hline Maternal education & & & & & & & $<0.001$ \\
\hline Primary school & $125(4.1)$ & $75 \quad(2.7)$ & $512(26.8)$ & $28 \quad(5.9)$ & $39 \quad(6.3)$ & $28 \quad(2.4)$ & \\
\hline $\begin{array}{l}\text { Secondary } \\
\text { school }\end{array}$ & $1950(63.8)$ & $1615(57.2)$ & $1232(64.4)$ & $193(40.6)$ & $259(42.0)$ & $375(32.8)$ & \\
\hline College & 952 (31.1) & $1108(39.2)$ & $157 \quad(8.2)$ & $231(48.6)$ & $272(44.1)$ & $703(61.5)$ & \\
\hline Missing data & $31 \quad(1.0)$ & $26 \quad(0.9)$ & $11(0.6)$ & $23(4.8)$ & $47 \quad(7.6)$ & $37 \quad(3.2)$ & \\
\hline Siblings & & & & & & & $<0.001$ \\
\hline No & $2449(80.1)$ & 2469 (87.4) & $318(16.6)$ & $126(26.5)$ & $55 \quad(8.9)$ & $116(10.1)$ & \\
\hline Only younger & $280 \quad(9.2)$ & 121 & $655(34.3)$ & $141(29.7)$ & $218(35.3)$ & $361(31.6)$ & \\
\hline Only older & $262(8.6)$ & $166 \quad(5.9)$ & $720(37.7)$ & $152(32.0)$ & $250(40.5)$ & $400(35.0)$ & \\
\hline $\begin{array}{l}\text { Both younger } \\
\text { and older }\end{array}$ & $67 \quad(2.2)$ & $68 \quad(2.4)$ & $219(11.5)$ & $56(11.8)$ & $94(15.2)$ & $266(23.3)$ & \\
\hline No. of siblings & & & & & & & $<0.001$ \\
\hline 0 & $2449(80.1)$ & 2469 (87.4) & $318(16.6)$ & $126(26.5)$ & $55 \quad(8.9)$ & $116(10.1)$ & \\
\hline 1 & $464(15.2)$ & $245 \quad(8.7)$ & $1047(54.8)$ & $227(47.8)$ & $315(51.1)$ & $428(37.4)$ & \\
\hline 2 & $97 \quad(3.2)$ & $54 \quad(1.9)$ & $406(21.2)$ & $83(17.5)$ & $174(28.2)$ & $366(32.0)$ & \\
\hline 3 & $48 \quad(1.6)$ & $56 \quad(2.0)$ & $141 \quad(7.4)$ & $39 \quad(8.2)$ & $73(11.8)$ & $233(20.4)$ & \\
\hline $\begin{array}{l}\text { Parental smoker } \\
\text { at home }\end{array}$ & 2076 (67.9) & $1995(70.6)$ & $590(30.9)$ & $124(26.1)$ & $146(23.7)$ & $301(26.3)$ & $<0.001$ \\
\hline Truck exposure§ & 1019 (33.3) & 1119 (39.6) & $554(29.0)$ & 85 (17.9) & $144(23.3)$ & $310(27.1)$ & $<0.001$ \\
\hline $\begin{array}{l}\text { Cat or dog at } \\
\text { home }\end{array}$ & $890(29.1)$ & $1348(47.7)$ & $225(11.8)$ & $97(20.4)$ & $155(25.1)$ & $616(53.9)$ & $<0.001$ \\
\hline
\end{tabular}

Note: $\mathrm{BMI}=$ body mass index, IQR = interquartile range.

*Unless indicated otherwise.

tData for sex were missing for 2 children from Beijing.

¥Cut-points for overweight were $21.91 \mathrm{~kg} / \mathrm{m}^{2}$ for boys aged 13 years, $22.62 \mathrm{~kg} / \mathrm{m}^{2}$ for boys aged 14 years, $22.58 \mathrm{~kg} / \mathrm{m}^{2}$ for girls aged 13 years and $23.34 \mathrm{~kg} / \mathrm{m}^{2}$ for girls aged 14 years. ${ }^{20}$ Cut-points for obesity were $26.84 \mathrm{~kg} / \mathrm{m}^{2}$ for boys aged 13 years, $27.63 \mathrm{~kg} / \mathrm{m}^{2}$ for boys aged 14 years, $27.76 \mathrm{~kg} / \mathrm{m}^{2}$ for girls aged 13 years and $28.57 \mathrm{~kg} / \mathrm{m}^{2}$ for girls aged 14 years. ${ }^{20}$

§Trucks passing the residential street frequently or almost the whole day. 


\section{Ever wheezing}

\begin{tabular}{|c|c|c|c|c|}
\hline \multirow[b]{2}{*}{ Group } & \multicolumn{4}{|c|}{ Adolescent boys } \\
\hline & $\begin{array}{c}\text { No. of } \\
\text { adolescents }\end{array}$ & $\begin{array}{l}\text { Adjusted* OR } \\
\quad(95 \% \mathrm{Cl})\end{array}$ & $\begin{array}{r}\text { Decreased } \\
\text { risk }\end{array}$ & $\begin{array}{l}\text { Increased } \\
\text { risk } \\
\longrightarrow\end{array}$ \\
\hline \multicolumn{5}{|l|}{ Vancouver } \\
\hline Canadian-born non-Chinese & 618 & $4.24(3.06-5.85)$ & & \multirow{2}{*}{ 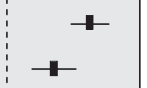 } \\
\hline Canadian-born Chinese & 331 & $2.27(1.55-3.33)$ & & \\
\hline Chinese immigrant & 250 & $1.57(1.02-2.41)$ & & 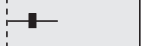 \\
\hline \multicolumn{5}{|l|}{ China } \\
\hline Native Chinese, Hong Kong & 943 & $1.95(1.45-2.61)$ & \multicolumn{2}{|r|}{ 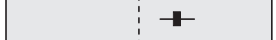 } \\
\hline Native Chinese, Beijing & 1437 & $1.06(0.83-1.36)$ & \multicolumn{2}{|c|}{$\rightarrow$} \\
\hline \multirow[t]{3}{*}{ Native Chinese, Guangzhou } & 1483 & 1.0 (ref) & \multicolumn{2}{|c|}{ 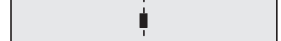 } \\
\hline & & & & \\
\hline & & & \multicolumn{2}{|c|}{ Adjusted* OR $(95 \% \mathrm{Cl}$} \\
\hline
\end{tabular}

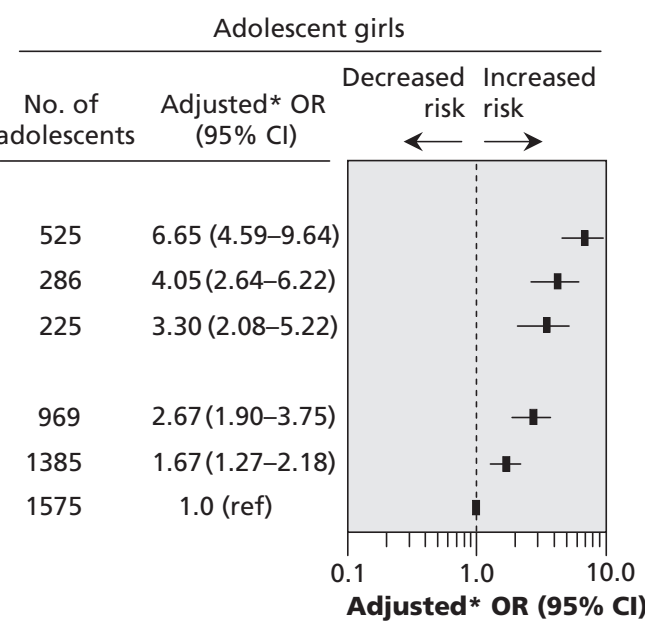

\section{Current wheezing}

\begin{tabular}{|c|c|c|c|c|}
\hline \multirow[b]{2}{*}{ Group } & \multicolumn{4}{|c|}{ Adolescent boys } \\
\hline & $\begin{array}{c}\text { No. of } \\
\text { adolescents }\end{array}$ & $\begin{array}{c}\text { Adjusted* OR } \\
(95 \% \mathrm{Cl})\end{array}$ & $\begin{array}{r}\text { Decreased } \\
\longleftarrow\end{array}$ & $\begin{array}{l}\text { Increased } \\
\text { risk } \\
\longrightarrow\end{array}$ \\
\hline \multicolumn{5}{|l|}{ Vancouver } \\
\hline Canadian-born non-Chinese & 618 & $3.05(2.02-4.61)$ & & $\rightarrow-$ \\
\hline Canadian-born Chinese & 331 & $1.93(1.18-3.15)$ & & $\rightarrow$ \\
\hline Chinese immigrant & 250 & $1.45(0.83-2.54)$ & & 1 \\
\hline \multicolumn{5}{|l|}{ China } \\
\hline Native Chinese, Hong Kong & 943 & $1.66(1.13-2.43)$ & & $\rightarrow$ \\
\hline Native Chinese, Beijing & 1437 & $1.18(0.86-1.62)$ & & - \\
\hline \multirow[t]{2}{*}{ Native Chinese, Guangzhou } & 1483 & 1.0 (ref) & & $i$ \\
\hline & & & 0.1 & 1.0 \\
\hline
\end{tabular}

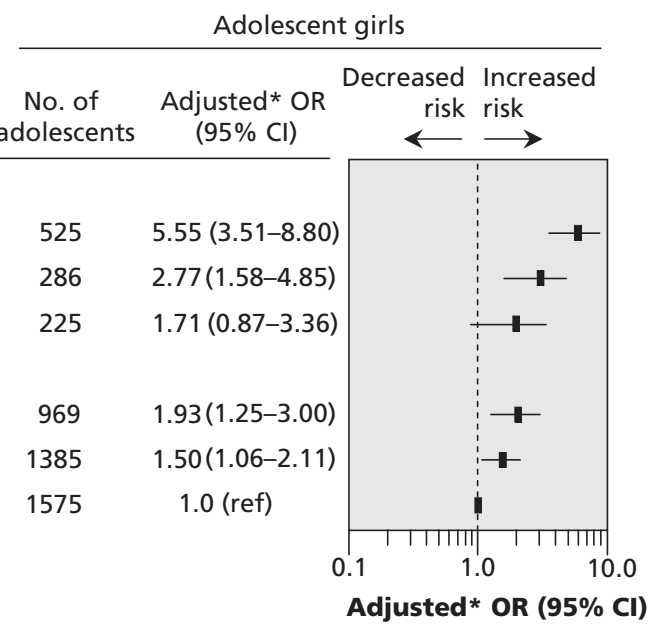

Ever asthma

\begin{tabular}{|c|c|c|c|c|}
\hline \multirow[b]{2}{*}{ Group } & \multicolumn{4}{|c|}{ Adolescent boys } \\
\hline & $\begin{array}{l}\text { No. of } \\
\text { adolescents }\end{array}$ & $\begin{array}{c}\text { Adjusted* OR } \\
s \quad(95 \% \mathrm{Cl})\end{array}$ & $\begin{array}{r}\text { Decreased } \\
\text { risk }\end{array}$ & $\begin{array}{l}\text { Increased } \\
\text { risk } \\
\longrightarrow\end{array}$ \\
\hline \multicolumn{5}{|l|}{ Vancouver } \\
\hline Canadian-born non-Chinese & 618 & $2.83(1.91-4.18)$ & & $\rightarrow$ \\
\hline Canadian-born Chinese & 331 & $2.72(1.75-4.23)$ & & 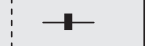 \\
\hline Chinese immigrant & 250 & $1.29(0.75-2.25)$ & & - \\
\hline \multicolumn{5}{|l|}{ China } \\
\hline Native Chinese, Hong Kong & 943 & $2.66(1.87-3.77)$ & & $\rightarrow$ \\
\hline Native Chinese, Beijing & 1437 & $1.11(0.82-1.50)$ & & - \\
\hline \multirow[t]{2}{*}{ Native Chinese, Guangzhou } & 1483 & 1.0 (ref) & & $i$ \\
\hline & & & 111 & \\
\hline
\end{tabular}

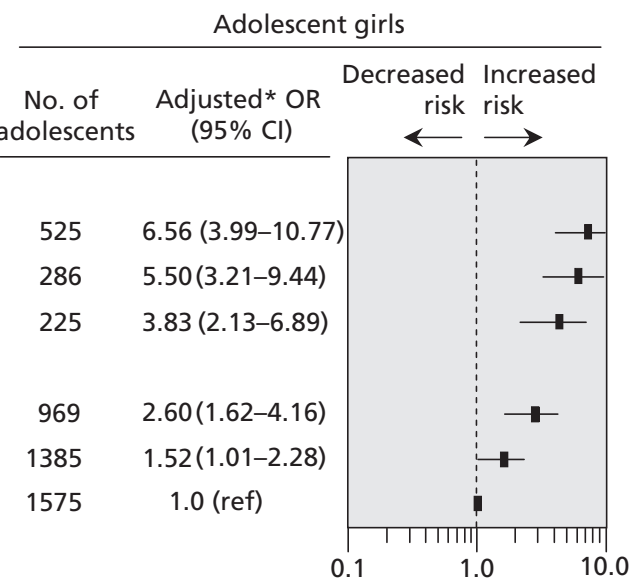

Adjusted* OR (95\% Cl)

Figure 2: Results of multivariable logistic regression analysis for prevalence of wheezing and asthma among 13- and 14-year-old children in China and Vancouver, Canada. *Adjusted for body mass index, maternal education, number and order of siblings, parental smoking, truck exposure and pets at home. Further data are presented in Appendices 2 and 3 (available at www.cmaj.ca/cgi/content /full/179/11/1133/DC2). Note: $\mathrm{Cl}=$ confidence interval, $\mathrm{OR}=$ odds ratio. 
More than 12 wheezing attacks per year

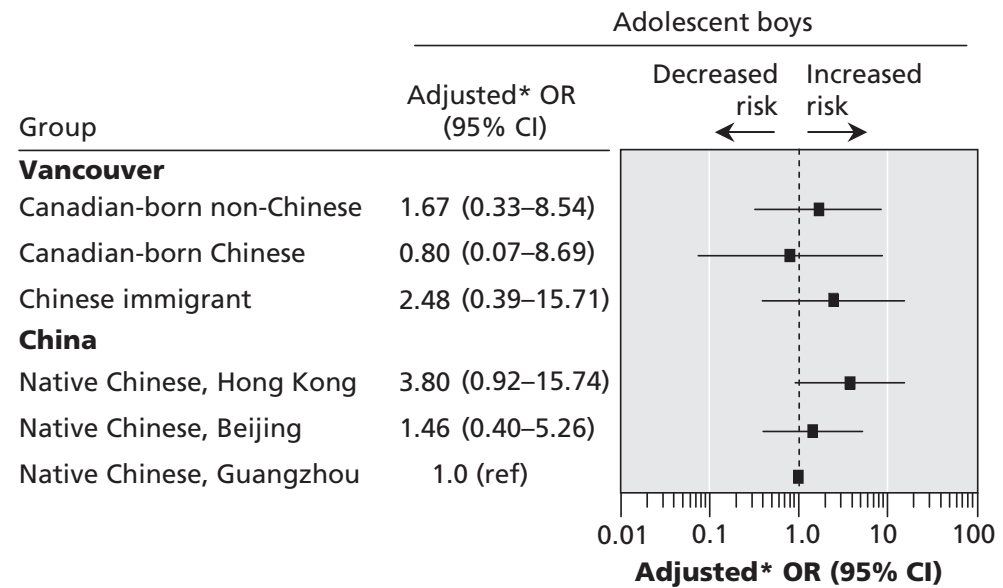

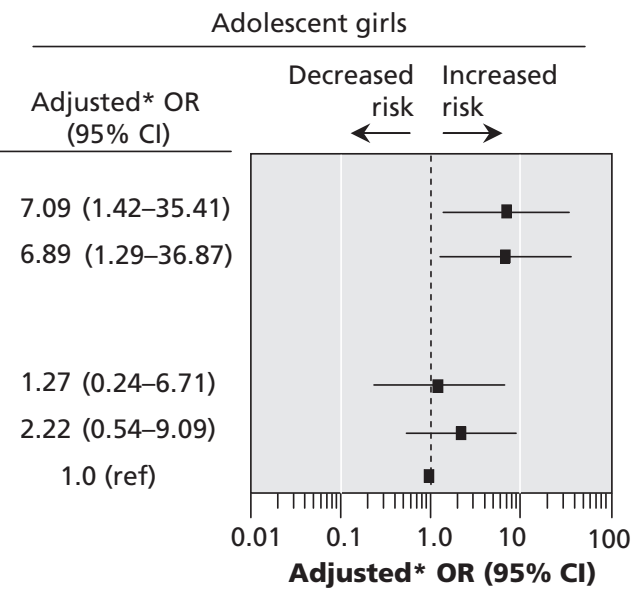

Woken by wheezing more than once per week
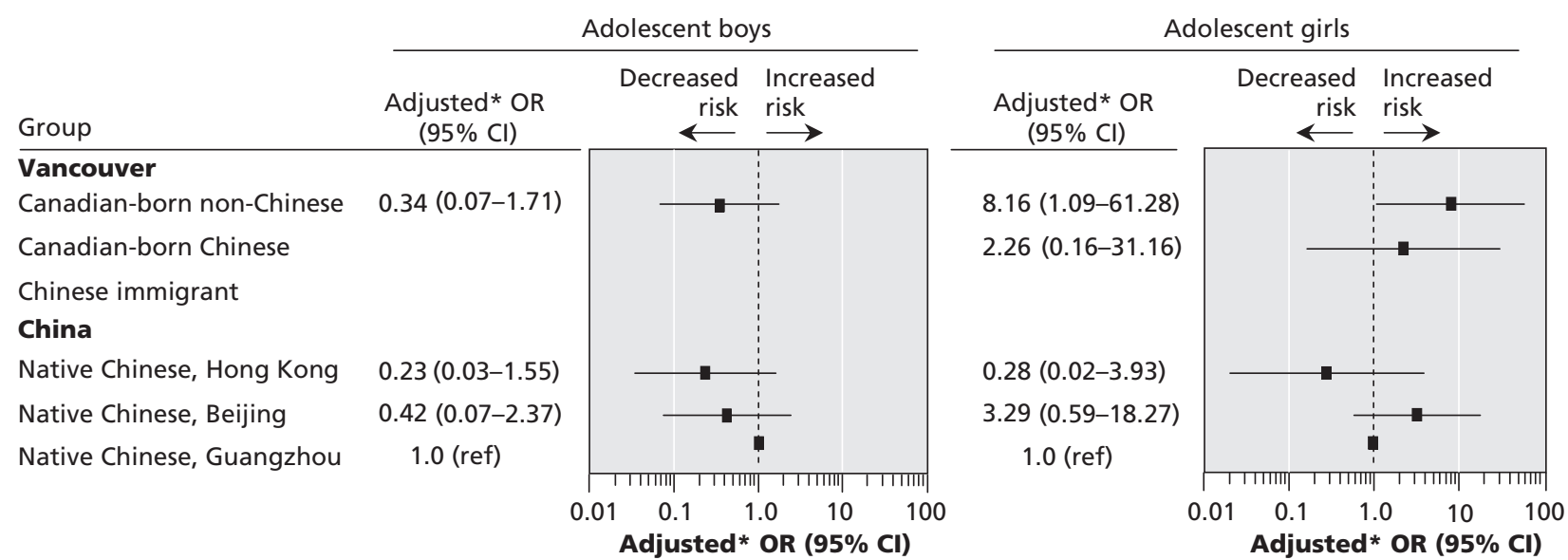

Wheezing attacks that limit speech

\begin{tabular}{|c|c|c|c|}
\hline \multirow[b]{2}{*}{ Group } & \multicolumn{3}{|c|}{ Adolescent boys } \\
\hline & $\begin{array}{c}\text { Adjusted* OR } \\
(95 \% \mathrm{CI})\end{array}$ & $\begin{array}{r}\text { Decreased } \\
\longleftarrow \text { risk }\end{array}$ & $\begin{array}{l}\text { Increased } \\
\text { risk } \\
\stackrel{ }{\longrightarrow}\end{array}$ \\
\hline \multicolumn{4}{|l|}{ Vancouver } \\
\hline Canadian-born non-Chinese & $3.00(0.88-10.27)$ & & \\
\hline Canadian-born Chinese & $1.71(0.36-8.18)$ & & \\
\hline Chinese immigrant & $5.43(1.52-19.31)$ & & $\longrightarrow$ \\
\hline \multicolumn{4}{|l|}{ China } \\
\hline Native Chinese, Hong Kong & $3.76(1.21-11.64)$ & & $\longrightarrow$ \\
\hline Native Chinese, Beijing & $1.00(0.33-3.01)$ & & \\
\hline \multirow[t]{2}{*}{ Native Chinese, Guangzhou } & 1.0 (ref) & & 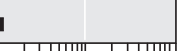 \\
\hline & & $0.1 \quad 1$ & $\begin{array}{lll}0 & 10 & 100\end{array}$ \\
\hline
\end{tabular}

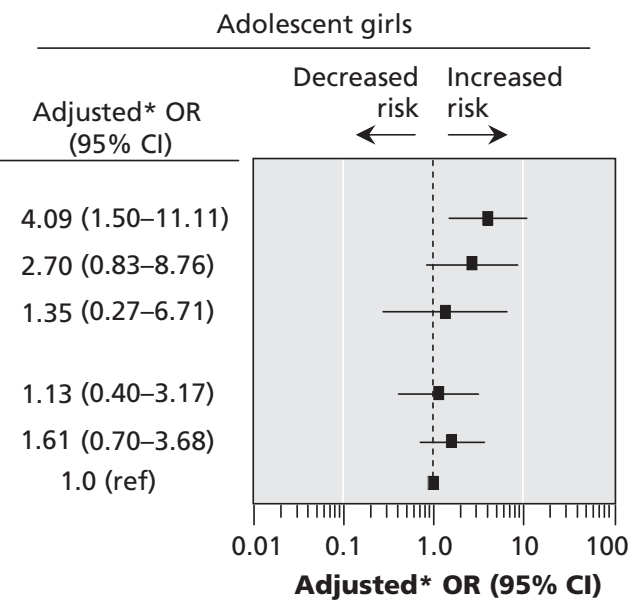

Figure 3: Results of multivariable logistic regression analysis for prevalence rates of severe asthma among 13- and 14-year-old children in China and Vancouver. *Adjusted for body mass index, maternal education, number and order of siblings, parental smoking, truck exposure and pets at home. Further data are presented in Appendix 4 (available at www.cmaj.ca/cgi/content/full/179/11/1133/DC2). Note: The number of adolescents in each group was as listed in Figure 2. $\mathrm{Cl}=$ confidence interval, OR = odds ratio. 
than among those living in China and was least common for those living in Hong Kong. More than $80 \%$ of native Chinese adolescents living in Beijing and Guangzhou had no siblings, whereas $26.5 \%$ of Chinese immigrants to Canada, $16.6 \%$ of native Chinese living in Hong Kong and about $10 \%$ of Chinese and non-Chinese Canadian-born adolescents had no siblings. A greater proportion of adolescents in Guangzhou and Beijing than in Hong Kong or Vancouver were exposed to parental smoking at home. Truck exposure on weekdays was more common in China. Nearly $48 \%$ of the adolescents in Beijing had pets at home, but only $11.8 \%$ of those in Hong Kong and 20\%-30\% of the other 3 groups of Chinese adolescents had pets. In Vancouver, 53.9\% of non-Chinese adolescents had pets.

\section{Prevalence of asthma}

Univariable analyses showed no significant differences in prevalence rates of overall asthma symptoms among schools within each centre; therefore, we did not adjust for school in the multivariable analyses. None of the potential confounding factors except sex were significantly associated with all asthma symptoms, but we found significant interactions between sex and subgroup for the prevalence of ever wheezing, current wheezing and ever having had asthma. We therefore analyzed the data for each sex separately. Multivariable analyses adjusted for all confounding factors did not change the overall direction of gradients for the prevalence rates among groups.

For both sexes, we found increasing gradients in the prevalence rates of ever wheezing, current wheezing and ever having had asthma among Chinese adolescents according to residence (Figure 2; Appendices 2 and 3, available at www.cmaj .ca/cgi/content/full/179/11/1133/DC2). The prevalence rates were lowest among native Chinese adolescents living in mainland China, greater among Chinese immigrants living in Vancouver and native Chinese adolescents living in Hong Kong, and highest among Canadian-born Chinese adolescents living in Vancouver. For girls, but not boys, these asthma symptoms were significantly more prevalent among native Chinese adolescents living in Beijing than among those living in Guangzhou. There were similar consistent trends toward increased prevalence of ever wheezing, current wheezing and ever having had asthma among the population groups, although not all of the differences were significant. However, we found no consistent patterns in the prevalence rates of exercise-induced wheezing and current nocturnal coughing among the 5 groups of Chinese adolescents.

The prevalence rates of all asthma-related symptoms except exercise-induced wheezing were higher among nonChinese Canadian-born adolescents in Vancouver than in any of the 5 groups of Chinese adolescents.

\section{Asthma severity}

We defined severe wheezing as one or more of the following symptoms: wheezing attacks more than 12 times per year, being awakened by wheezing more than once per week or wheezing attacks that limited speech. Trends in severe wheezing were inconsistent by sex across population groups (Figure 3; Appendix 4, available online at www.cmaj.ca /cgi/content/full/179/11/1133/DC2). The prevalence rate of wheezing attacks more than 12 times a year was highest among Chinese boys in Hong Kong $(p=0.07)$ and among Canadian-born Chinese girls $(p=0.020)$ and non-Chinese girls $(p=0.020)$. No significant differences were found in nocturnal awakening more than once a week among native Chinese adolescents in Guangzhou, Beijing and Hong Kong. This symptom was virtually not reported by Chinese immigrants living in Vancouver. The risk of severe wheezing affecting speech was significantly greater for Chinese boys in Hong Kong $(p=0.020)$ and for male immigrants to Canada $(p=0.009)$, but not for girls in these groups.

\section{Asthma symptoms and duration of residence in Canada}

The median duration of residence in Canada among Chineseborn adolescents who had immigrated to Vancouver was 7.0 years. This value was used to subdivide the participants living in Vancouver, as described in the Methods section. Among Chinese adolescents of both sexes in Vancouver, the prevalence of ever wheezing was $14.5 \%$ for immigrants with less than 7 years in Canada, $18.8 \%$ for those with 7 or more years 
in Canada and $20.9 \%$ of those born in Canada ( $p=0.020$ for trend). Similarly, the prevalence of ever having had asthma was $7.7 \%$ for immigrants with less than 7 years in Canada, $11.2 \%$ for those with 7 or more years in Canada and $15.9 \%$ for those born in Canada ( $p=0.006$ for trend) (Table 3). When stratified by sex, these symptoms showed consistent gradients of increasing prevalence, but the trend was significant only for boys who had ever had asthma ( $p=0.010)$. There were no consistent trends in the prevalence rates for current wheezing, exercise-induced wheezing and nocturnal coughing with increased duration of residence in Canada.

\section{Interpretation}

The present study confirmed a lower prevalence of asthma symptoms among Chinese adolescents born in mainland China and a significantly higher prevalence among Chinese adolescents born in Hong Kong and Canada. These results suggest that early environmental exposure reduced the subsequent development of asthma, despite similar genetic background..$^{21}$ However, the environment continues to be an important factor influencing the prevalence of asthma and atopy even after the early years of sensitization. ${ }^{22,23}$ Among Chinese adolescents in Vancouver, we observed increasing prevalence of ever wheezing and ever having had asthma with longer duration of residence in Canada, although most trends did not achieve significance when stratified by sex, possibly because of sample sizes. A trend toward higher prevalence of asthma and allergic disease among Chinese adolescents living in affluent communities was evident in phase 1 of the International Study of Asthma and Allergies in Childhood. ${ }^{2,24}$ The prevalence rates of current wheeze in 13- and 14-year-old schoolchildren, as identified by written questionnaires, were $12.4 \%$ in Hong Kong and $4.2 \%$ in mainland China. ${ }^{2}$ Data from phase 2 of the study suggested that environmental factors and diet could partly explain the difference in prevalence of asthma between children living in Hong Kong and those living in mainland China (Beijing and Guangzhou). Phase 2 showed that factors significantly associated with current wheeze were cooking with gas (OR 2.04, 95\% CI 1.34-3.13), use of foam pillows (OR 2.58, 95\% CI 1.66-3.99) and living in damp housing (OR 1.89, 95\% CI 1.26-2.83), whereas factors protecting against current wheeze were use of cotton quilts and the consumption of fruit and raw vegetables..$^{25,26}$

In contrast, current nocturnal coughing and current exercise-induced wheezing showed no significant gradients among the different groups of Chinese adolescents. In a previous report, nocturnal coughing had the lowest predictive value for bronchial hyperresponsiveness. ${ }^{27}$ This symptom may reflect respiratory conditions other than asthma, ${ }^{2}$ yet exerciseinduced wheezing was the second-best predictor for bronchial hyperresponsiveness. ${ }^{27}$ Among the Chinese adolescents in our study, exercise-induced wheezing was more common than ever wheezing or current wheezing or ever having had asthma. This phenomenon was also seen in phase 1 of the International Study of Asthma and Allergies in Childhood ${ }^{2,21}$ and in a survey of adolescents in schools in Shanghai, China. ${ }^{28}$ The reason for the discrepancy remains unclear. It may be real, it may represent overreporting by adolescents or it may reflect participants' interpretation of the questions about wheezing. ${ }^{2}$ The validity of exercise-induced wheezing in epidemiologic studies of Chinese adolescents needs further investigation.

Improved hygiene and health care in western countries has altered the pattern of exposure to infectious agents, including Mycobacterium tuberculosis, parasites and endotoxins, in early life, possibly predisposing the immune system toward an atopic response. ${ }^{29,30}$ Although the prevalence of current wheezing showed an increasing gradient with greater "westernization" (Appendix 2 and Appendix 3, available at www.cmaj.ca/cgi/content/full/179/11/1133 /DC2), this trend was less evident for severe wheezing among boys. However, girls had higher rates of frequent wheezing episodes, nocturnal awakening and wheeze that limited speech, which suggests a potential effect of sex or other factors, including treatment, on the severity of asthma, rather than only a "westernization" effect.

Migrating populations with stable genetics provide an opportunity to observe changes in disease with changes in environment, just as genetically different groups living in the same region allow study of the effects of genetic diversity. Increases in asthma symptoms related to migration from developing to industrialized areas has been reported from several countries and regions, including New Zealand, ${ }^{31}$ Sweden, ${ }^{32,33}$ Australia, ${ }^{34-36}$ Italy, ${ }^{37,38}$ the United Kingdom, ${ }^{39-41}$ Israel, ${ }^{42}$ Europe $^{43}$ and the United States. ${ }^{44,45}$ The prevalence of asthma in Asian populations has repeatedly been shown to be lower than that in the West, but variations exist within Asian countries. ${ }^{1,19,46}$ Cultural, dietary, economic and geographic factors, as well as the variability in distributions of characteristics related to country of birth, residential history, linguistic differences and degree of acculturation to a western lifestyle, may account for differences between ethnic subgroups. ${ }^{46,47}$ Interactions among genetic, environmental and social factors have also been postulated to explain the observed differences. ${ }^{19}$

There are many sociologic and cultural differences among the populations that we studied. More than $80 \%$ of native Chinese adolescents living in mainland China, but only $16.6 \%$ of those in Hong Kong and about $10 \%$ of those in Canada, had no siblings. Of mothers in Canada, $40 \%$ to $60 \%$ had received a college education, compared with $30 \%$ to $40 \%$ in mainland China and only $8.2 \%$ in Hong Kong. Nearly $70 \%$ of native Chinese adolescents in mainland China, but only $25 \%$ to $30 \%$ of those in Hong Kong and Canada, had exposure to environmental tobacco smoke in the home. More adolescents in China than in Canada had frequent exposure to trucks. Pet ownership was most common among adolescents in Beijing and non-Chinese adolescents in Vancouver and least common for those living in Hong Kong. However, the differences in prevalence rates of asthma for adolescents in mainland China, Hong Kong and Canada remained significant after adjustment for these factors.

The use of "race" and "ethnicity" as predictive variables for describing populations is associated with problems because of the inherent difficulties of defining the terms.$^{48}$ Using "birthplace" as a variable could also be criticized because of 
differences between different groups of people from the same geographic region. ${ }^{49,50}$ Using a combination of these 2 variables to define populations may better reflect both genetic and environmental (residential) influences. Davis and associates ${ }^{46}$ suggested that, when possible, asthma surveys involving a substantial number of Asian respondents should use a more detailed categorization of race and ethnicity than the traditional category of "Asian." We used "Chinese" in our study, as this has been the principal group among the growing number of immigrants to Canada since $1986 .{ }^{15}$

\section{Strengths and limitations}

This comparative study had several strengths. Canada and China represent almost the extremes of asthma prevalence among 58 countries included in phase 3 of the International Study of Asthma and Allergies in Childhood. The data were collected almost contemporaneously using identical methodology in each centre. Also, we were able to examine the duration of residence in the new country (Canada). Differences in several demographic characteristics, including number of siblings, also provided unique data for further study.

Our study also had limitations. The ethnicity of participants was not recorded directly, but rather was determined by surname; as a result, $7.2 \%$ of participants in Canada were excluded because of uncertainty in classification. There may also have been misclassification bias. A Chinese surname would likely mean that the adolescent had at least a Chinese father but perhaps not a Chinese mother, whereas a child classified as "non-Chinese" by surname might have had a Chinese mother. Second, the original birthplace of Chinese immigrants in Vancouver was not collected, which might have introduced misclassification of years of residence in the West. All participants were born around 1987-1988, when Hong Kong was the major source of Chinese immigrants to Canada, but many of those with less than 7 years' residence in Canada might have come from mainland China. We excluded those with uncertainty regarding birthplace (Fig.1). Third, some important potential confounders were not recorded, including family history of asthma, family income, history of infectious disease and personal smoking. Finally, self-reported heights and weights might have been subject to reporting bias.

\section{Conclusions}

Further studies in China and Canada, including objective measures such as allergen skin prick test, bronchial hyperresponsiveness and environmental measurements (e.g., endotoxins and diesel exhaust particles) are necessary to identify the risk factors or protective factors associated with asthma. Moreover, the reason for differences between the sexes in the prevalence rates for native Chinese living in Guangzhou and in Beijing needs further investigation.

In conclusion, asthma symptoms in Chinese adolescents were lowest among those living in mainland China, were greater among those who lived in Hong Kong or who had immigrated to Canada during childhood, and were highest for those born in Canada. These findings strongly suggest that environmental factors and duration of exposure, in addition to genetic factors, influence the prevalence of asthma.
This article has been peer reviewed.

Competing interests: None declared.

Contributors: Hong-Yu Wang was responsible for collecting data in the phase 3 study of the International Study of Asthma and Allergies in Childhood in Guangzhou, was involved in conception and design of the analyses, performed data analysis and interpretation, and wrote and revised the manuscript. Gary Wong was a collaborator in the International Study of Asthma and Allergies in Childhood in Hong Kong, Yu-Zhi Chen was a collaborator in the study in Beijing, and Nan-Shan Zhong was a collaborator in the study in Guangzhou, and all 3 of these authors helped with the interpretation of the data and revision of the manuscript. Alexander Ferguson supervised data collection in Vancouver and Yu Ma supervised data collection in Beijing, and both of these authors helped with the interpretation of the data and revision of the manuscript. Justina Greene managed the Canadian data for the International Study of Asthma and Allergies in Childhood, performed data-merging, and assisted with the analysis and interpretation of the data and revision of the manuscript. Christopher Lai was regional coordinator of the International Study of Asthma and Allergies in Childhood for the Asia-Pacific region and also helped with the interpretation of the data and revision of the manuscript. Malcolm Sears was coordinator of the International Study of Asthma and Allergies in Childhood in Canada, developed the concept and designed the methodology for the analyses and was involved at all stages with interpretation of the data and writing the manuscript. All of the authors approved the final version of the manuscript for publication.

Acknowledgements: We thank Piush Mandane, Joanne Duncan and Mei Jiang for their technical support, and the children, parents and staff of each centre and each school in Canada and China for their participation in the study.

Funding: This study was supported by Health Canada and a Research Grants Council of Hong Kong Competitive Earmarked Research Grant to the Chinese University of Hong Kong, grant number 4512/06M.

\section{REFERENCES}

1. International Study of Asthma and Allergies in Childhood (ISAAC) Steering Committee. Worldwide variation in prevalence of symptoms of asthma, allergic rhinoconjunctivitis, and atopic eczema: ISAAC. Lancet 1998;351:1225-32.

2. International Study of Asthma and Allergies in Childhood Steering Committee. Worldwide variations in the prevalence of asthma symptoms: the International Study of Asthma and Allergies in Childhood (ISAAC). Eur Respir J 1998;12:315-35.

3. Platts-Mills TA, Carter MC. Asthma and indoor exposure to allergens. $N$ Engl J Med 1997;336:1382-4.

4. Hesselmar B, Aberg N, Aberg B, et al. Does early exposure to cat or dog protect against later allergy development? Clin Exp Allergy 1999;29:611-7.

5. Halken S, Host A, Nilsson L, et al. Passive smoking as a risk factor for development of obstructive respiratory disease and allergic sensitization. Allergy 1995;50:97-105.

6. Guo YL, Lin YC, Sung FC, et al. Climate, traffic-related air pollutants, and asthma prevalence in middle-school children in Taiwan. Environ Health Perspect 1999;107:1001-6.

7. Weiss ST, Gold DR. Gender differences in asthma. Pediatr Pulmonol 1995; 19:153-5.

8. Cassol VE, Rizzato TM, Teche SP, et al. [Prevalence and severity of asthma among adolescents and their relationship with the body mass index.] J Pediatr (Rio J) 2005;81:305-9. In Portuguese.

9. Wickens K, Crane J, Pearce N, et al. The magnitude of the effect of smaller family sizes on the increase in the prevalence of asthma and hay fever in the United Kingdom and New Zealand. J Allergy Clin Immunol 1999;104:554-8.

10. Cesaroni G., Farchi S, Davoli M, et al. Individual and area-based indicators of socioeconomic status and childhood asthma. Eur Respir J 2003;22:619-24.

11. Douwes J, Pearce N. Asthma and the westernization 'package.' Int J Epidemiol 2002;31:1098-102.

12. Strachan DP. Hay fever, hygiene and household size. BMJ 1989;299:1259-60.

13. Skeldon R. China: from exceptional case to global participant. In: Migration information source [Internet]. Washington: Migration Policy Institute; 2004. Available: www.migrationinformation.org/Feature/display.cfm?ID=219 (accessed 2008 Sep 12)

14. Skeldon R. Migration from China. J Int Aff 1996;49:434-55. [

15. Recent immigrants in metropolitan areas: Canada - a comparative profile based on the 2001 census. Ottawa: Citizenship and Immigration Canada; 2005. Available: www.cic.gc.ca/english/resources/research/census2001/canada/foreword.asp (accessed 2008 Sep 12).

16. Chen Y, Dales R, Tang M, et al. Sex-related interactive effect of smoking and household pets on asthma incidence. Eur Respir J 2002;20:1162-6.

17. International Study of Asthma and Allergies in Childhood Steering Committee. 
Phase three manual of the International Study of Asthma and Allergies in Childhood. Auckland (NZ): The Committee; 2000.

18. List of common Chinese surnames. Answers Corporation; 2008. Available: www.answers.com/topic/list-of-common-chinese-surnames (accessed 2008 Sep 12).

19. Leung R, Wong G, Lau J, et al. Prevalence of asthma and allergy in Hong Kong schoolchildren: an ISAAC study. Eur Respir J 1997;10:354-60.

20. Cole TJ, Bellizzi MC, Flegal KM, et al. Establishing a standard definition for child overweight and obesity worldwide: international survey. BMJ 2000;320:1240-3.

21. Wong GW, Leung TF, Ko FW, et al. Declining asthma prevalence in Hong Kong Chinese schoolchildren. Clin Exp Allergy 2004;34:1550-5.

22. Macaubas C, Prescott SL, Venaille TJ, et al. Primary sensitization to inhalant allergens. Pediatr Allergy Immunol 2000;11 Suppl 13:9-11.

23. Miles EA, Warner JA, Lane AC, et al. Altered T lymphocyte phenotype at birth in babies born to atopic parents. Pediatr Allergy Immunol 1994;5:202-8.

24. Chen YZ, Zhao TB, Yan D, et al. A questionnaire-based survey on prevalence of asthma, allergic rhinitis and eczema in five Chinese cities (ISAAC study). Chinese J Pediatr 1998;36:353-5.

25. Wong GW, Ko FW, Hui DS, et al. Factors associated with difference in prevalence of asthma in children from three cities in China: multicentre epidemiological survey. BMJ 2004;329:486-9.

26. Wang HY, Chen YZ, Ma Y, et al. Disparity of asthma prevalence in Chinese schoolchildren is due to differences in lifestyle factors. Chin J Pediatr 2006;44: 41-5.

27. Lai CK, Chan JK, Chan A, et al. Comparison of the ISAAC video questionnaire (AVQ3.0) with the ISAAC written questionnaire for estimating asthma associated with bronchial hyperreactivity. Clin Exp Allergy 1997;27:540-5.

28. Mi YH, Norbäck D, Tao J, et al. Current asthma and respiratory symptoms among pupils in Shanghai, China: influence of building ventilation, nitrogen dioxide, ozone, and formaldehyde in classrooms. Indoor Air 2006;16:454-6.

29. Martinez FD. Role of viral infections in the inception of asthma and allergies during childhood: Could they be protective? Thorax 1994;49:1189-91.

30. Holt PG. Environmental factors and primary T-cell sensitization to inhalant allergens in infancy: reappraisal of the role of infections and air pollution. Pediatr Allergy Immunol 1995;6:1-10.

31. Waite DA, Eyles EF, Tonkin SL, et al. Asthma prevalence in Tokelauan children in two environments. Clin Allergy 1980;10:71-5.

32. Hjern A, Rasmussen F, Hedlin G. Age at adoption, ethnicity and atopic disorder: a study of internationally adopted young men in Sweden. Pediatr Allergy Immunol 1999;10:101-6.

33. Hjern A, Haglund B, Bremberg S, et al. Social adversity, migration and hospital admissions for childhood asthma in Sweden. Acta Paediatr 1999;88:1107-12.

34. Leung RC, Carlin JB, Burdon JG, et al. Asthma, allergy and atopy in Asian immigrants in Melbourne. Med J Aust 1994;161:418-25.

35. Powell CV, Nolan TM, Carlin JB, et al. Respiratory symptoms and duration of residence in immigrant teenagers living in Melbourne, Australia. Arch Dis Child 1999;81:159-62.
36. Gibson PG, Henry RL, Shah S, et al. Migration to a western country increases asthma symptoms but not eosinophilic airway inflammation. Pediatr Pulmonol 2003;36:209-15

37. Tedeschi A, Barcella M, Bo GA, et al. Onset of allergy and asthma symptoms in extra-European immigrants to Milan, Italy: possible role of environmental factors. Clin Exp Allergy 2003;33:449-54.

38. Migliore E, Pearce N, Bugiani M, et al. Prevalence of respiratory symptoms in migrant children to Italy: the results of SIDRIA-2 study. Allergy 2007;62:293-300.

39. Ormerod LP, Myers P, Prescott RJ. Prevalence of asthma and 'probable' asthma in the Asian population in Blackburn. Respir Med 1999;93:16-20.

40. Netuveli G, Hurwitz B, Sheikh A. Ethnic variations in incidence of asthma episodes in England \& Wales: national study of 502,482 patients in primary care. Respir Res 2005;6:120.

41. Kuehni CE, Strippoli MP, Low N, et al. Asthma in young south Asian women living in the United Kingdom: the importance of early life. Clin Exp Allergy 2007:37:47-53.

42. Rosenberg R, Vinker S, Zakut H, et al. An unusually high prevalence of asthma in Ethiopian immigrants to Israel. Fam Med 1999;31:276-9.

43. Tobias A, Soriano JB, Chinn S, et al; European Community Respiratory Health Survey. Symptoms of asthma, bronchial responsiveness and atopy in immigrants and emigrants in Europe. European Community Respiratory Health Survey. Eur Respir J 2001;18:459-65.

44. Holguin F, Mannino DM, Antó J, et al. Country of birth as a risk factor for asthma among Mexican Americans. Am J Respir Crit Care Med 2005;171:103-8.

45. Eldeirawi K, McConnell R, Freels S, et al. Associations of place of birth with asthma and wheezing in Mexican American children. $J$ Allergy Clin Immunol 2005; 116:42-8.

46. Davis AM, Kreutzer R, Lipsett M, et al. Asthma prevalence in Hispanic and Asian American ethnic subgroups: results from the California Healthy Kids Survey. Pediatrics 2006;118:e363-70.

47. Reeves TJ, Bennett CE. We the people: Asians in the United States. Census 2000 Special Reports. Washington: US Department of Commerce, US Census Bureau; 2004. Available from: www.census.gov/prod/2004pubs/censr-17.pdf (accessed 2008 Sep 25).

48. Senior PA, Bhopal R. Ethnicity as a variable in epidemiological research. $B M J$ 1994;309:327-30.

49. Chong TM. Pattern of bronchial asthma in Singapore. Singapore Med J 1972; 13:154-60.

50. Ross I. Bronchial asthma in Malaysia. Br J Dis Chest 1984;78:369-75.

Correspondence to: Malcolm R. Sears, Firestone Institute for Respiratory Health, St. Joseph's Healthcare, 50 Charlton Ave. E., Hamilton ON L8N 4A6; fax: 905 521-6132; searsm@mcmaster.ca

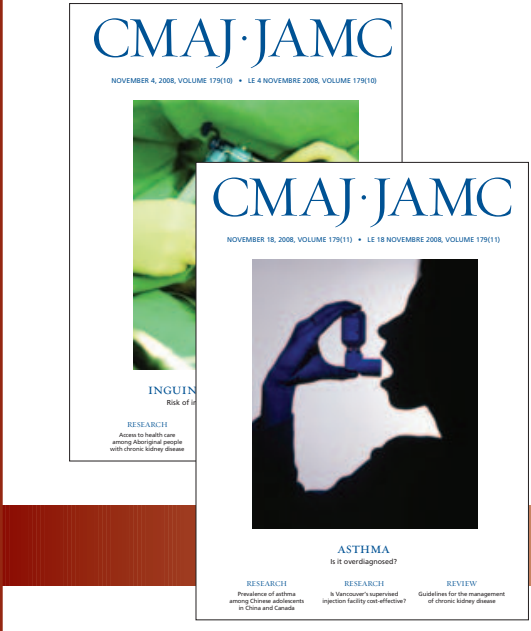

\section{Online manuscript submission and peer review available for $C M A J$}

\section{http://mc.manuscriptcentral.com/cmaj}

